\title{
An Empirical Analysis on the Leading Role of State-Owned Cultural Enterprises in the Chinese Cultural Industry
}

\author{
Yu Pingan \\ Economics Institute, Shanghai University, Shanghai, China
}

Email address:

280629652@qq.com

To cite this article:

Yu Pingan. An Empirical Analysis on the Leading Role of State-Owned Cultural Enterprises in the Chinese Cultural Industry. International Journal of Economics, Finance and Management Sciences. Vol. 3, No. 5, 2015, pp. 650-653. doi: 10.11648/j.ijefm.20150305.42

\begin{abstract}
According to China's national conditions and policy orientation, the state-owned cultural enterprises will occupy the leading role in the cultural industry for a long time, its development has become a hot spot of concern. This paper is to calculate the correlation degree between the state-owned and the non-state-owned cultural enterprises through the Grey Relational Analysis method. It's more convincing to analyze the influence that state-owned cultural enterprises impact on the cultural industry. It is aimed at discovering problems and making suggestions based on the data, and helping the development of state-owned cultural enterprises and better play the leading role.
\end{abstract}

Keywords: Cultural Industry, State-Owned Cultural Enterprises, Cultural System Reform, Leading Role

\section{Introduction}

The cultural system reform is a hot topic in China. In this context, the development of state-owned cultural enterprises is very worthy of attention. According to China's national conditions and policy orientation, the state-owned cultural enterprises will occupy the leading role in the cultural industry for a long time. The construction of state-owned cultural enterprises have been related to the consolidation and expansion of cultural reform achievement.

In view of this, analyzing the influence of state-owned cultural enterprises on the development of culture industry is significant. But at present, there are not many researches in this area, and most of them stay at the theoretical level. So it is necessary to analyze the influence from the empirical angle.

\section{Historical Review}

Chinese cultural industry had been in the institutional environment of planned economy for a long time, while the cultural industry developed rapidly in many western developed countries [1].

The government began to take measures when noted the importance of the cultural industry. From 1980s to 2003, with the deepening of China's economic system reform, the cultural system reform is also in exploration [2].

The cultural system reform started in 2003. It entered in the new stage of enlarging the involved population as well as the scale in 2006. With the state-owned cultural units complete the transformation, the main task of the cultural system reform has changed to deepen the reform [3].

\section{Present Status}

National Bureau of statistics recognized as cultural and related industries reached to 41351 units in 2013. Among them, the number of state-owned cultural enterprises is 5791, increased by $7.4 \%$ compared with 2012 .

\subsection{Output and Profit}

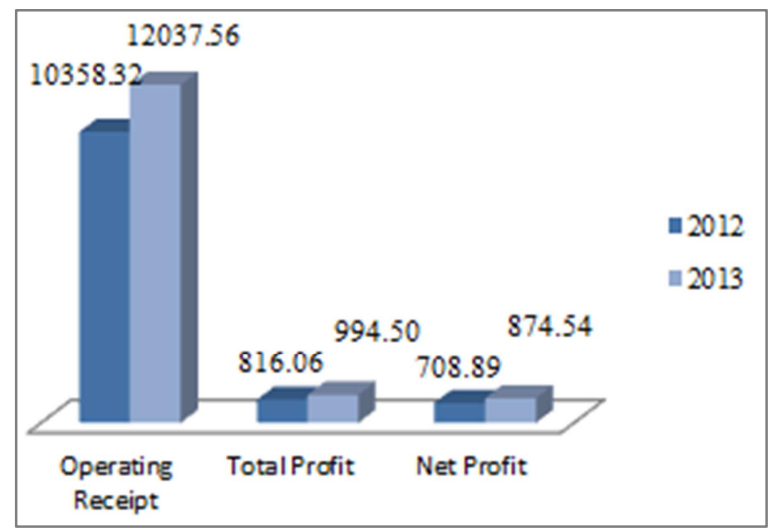

Figure 1. Growth of major economic indicators (unit: ten million). 
The output and profit of the state-owned cultural enterprises have maintained a certain degree of growth. The operating receipt reached to 1203.75 billion, increased by $16.2 \%$ in 2013; on the other hand, the total profit and net profit increased by $21.9 \%$ and $23.4 \%$ compared with 2012 respectively.

\subsection{Contrast of the Economic Indicators}

The major economic index between state-owned and non-state-owned cultural enterprises displayed in figure 2 . It can be seen that the state-owned cultural enterprises actually achieve growth compared to 2012, but there is still a certain gap with the non-state-owned cultural enterprises.

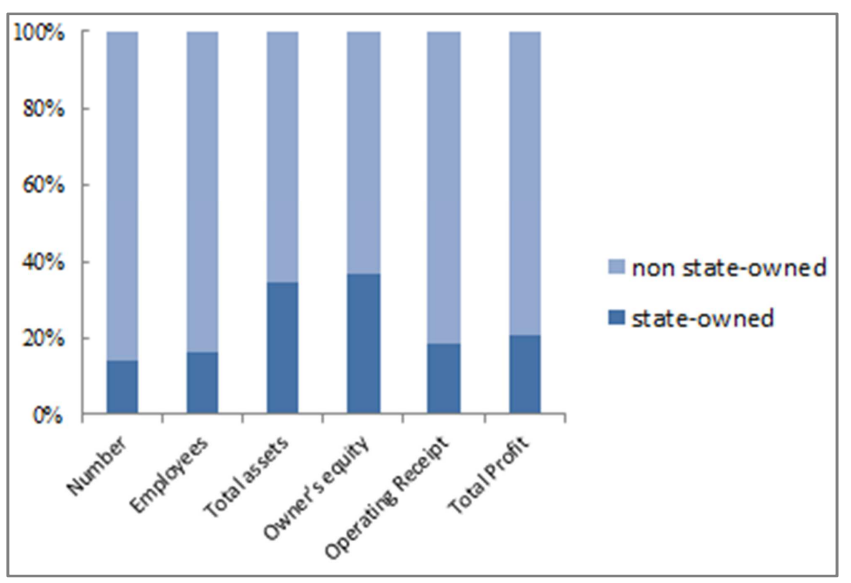

Figure 2. Economic index contrast.

\section{Experimental Method}

\subsection{Figure}

Although many indicators can represent the development of state-owned cultural enterprises, this chapter chooses one of the main indicators - added value. The sample data used in this study was the added value of the cultural enterprises in 2013. The data comes from the National Bureau of statistics.

This paper fractionize the cultural industry into ten main segments: 1, Press and publication industry; 2, Radio, TV and movie industry; 3, Cultural and artistic industry; 4, Cultural information transmission industry; 5, cultural and creative industry; 6,Cultural entertainment industry; 7 , arts and crafts industry; 8, Auxiliary production of cultural products industry; 9, Production of cultural products industry; 10 , Production of cultural equipment industry.

\subsection{The Grey Relational Analysis Method}

The grey theory, first proposed by Deng [4], avoids the inherent defects of conventional of statistical methods, and only requires a limited amount of data to estimate the behavior of an uncertain system.

The Grey correlation analysis method is determining the contribution of the factors to the system's main character by the grey relation degree. The grey relational coefficient is calculated from the normalized experimental data to express the relationship between the desired and actual experimental data. Then, the grey relational grade is computed by averaging the grey relational coefficient corresponding to each process response [5].

Due to the late development of the cultural industry, the relevant data of the state-owned cultural enterprises are more difficult to acquire. In order to make the results more scientific and reasonable, this paper uses the gray correlation degree analysis method.

Specific steps are as follows:

The first step is to confirm the reference sequence. This paper takes the added value $\mathrm{X}_{0}$ of the cultural industry as the primary sequences, the comparative sequence $X_{i}$ is the added value of the six holding types enterprises.

The second step is dimensionless method. In order to better carry out the comprehensive analysis, this paper processes the original data by equalization. All the data divided by the average value of the same series, a new series arising therefrom.

The grey-relational coefficient (GRC) represent the relationship between the control type and the subdivision types [6].

$$
\xi_{0 \mathrm{i}}(\mathrm{k})=\frac{\Delta_{0 \mathrm{i}}(\min )+\rho \times \Delta_{0 \mathrm{i}}(\max )}{\left\|\mathrm{X}_{0}(\mathrm{k})-\mathrm{X}_{\mathrm{i}}(\mathrm{k})\right\|+\rho \times \Delta_{0 \mathrm{i}}(\max )}
$$

Where $\rho$ is the distinguishing coefficient set between zero and one, in our case it was set to $\rho=0.5 ; \Delta_{0 \mathrm{i}}(\min )=$ $\min _{\mathrm{i}} \min _{\mathrm{k}}\left|\mathrm{X}_{0}(\mathrm{k})-\mathrm{X}_{\mathrm{i}}(\mathrm{k})\right|$ is the smallest value of $\Delta_{0 \mathrm{i}}$ and $\Delta_{0 \mathrm{i}}(\max )=\max _{\mathrm{i}} \max _{\mathrm{k}}\left|\mathrm{X}_{0}(\mathrm{k})-\mathrm{X}_{\mathrm{i}}(\mathrm{k})\right|$ is the largest value of $\Delta_{0 i}$.

Last step is to calculate the equal relational grade:

$$
r_{0 i}=\frac{1}{n} \sum_{i=0}^{n} \xi_{0 i}(k)
$$

\subsection{Analysis of Experimental Results}

Using formulas above, the experimental results can be calculated showing in the tables as follows.

Table 1. The consequence of dimensionless method.

\begin{tabular}{llllllll}
\hline Industry & $\boldsymbol{X}_{\mathbf{0}}$ & $\boldsymbol{X}_{\mathbf{1}}$ & $\boldsymbol{X}_{\mathbf{2}}$ & $\boldsymbol{X}_{\mathbf{3}}$ & $\boldsymbol{X}_{\mathbf{4}}$ & $\boldsymbol{X}_{\mathbf{5}}$ & $\boldsymbol{X}_{\mathbf{6}}$ \\
\hline 1 & 0.582 & 0.480 & 0.009 & 0.025 & 0.000 & 0.005 & 0.063 \\
2 & 0.277 & 0.164 & 0.004 & 0.070 & 0.003 & 0.001 & 0.036 \\
3 & 0.072 & 0.041 & 0.001 & 0.022 & 0.001 & 0.001 & 0.007 \\
4 & 1.090 & 0.334 & 0.003 & 0.168 & 0.529 & 0.026 & 0.031 \\
5 & 1.731 & 0.541 & 0.040 & 0.612 & 0.205 & 0.197 & 0.136 \\
6 & 0.308 & 0.116 & 0.018 & 0.130 & 0.013 & 0.009 & 0.023 \\
7 & 1.229 & 0.077 & 0.028 & 0.790 & 0.177 & 0.089 & 0.067 \\
8 & 1.234 & 0.241 & 0.050 & 0.661 & 0.131 & 0.086 & 0.065 \\
9 & 2.969 & 0.342 & 0.112 & 1.258 & 0.498 & 0.603 & 0.157 \\
10 & 0.508 & 0.018 & 0.004 & 0.198 & 0.070 & 0.201 & 0.016 \\
\hline
\end{tabular}

Table 3 shows the experimental results for the equal relational grade : $r_{03}>r_{01}>r_{04}>r_{05}>r_{06}>r_{02}$. A higher value of the grey relational grade represents a stronger relational degree between the reference sequence $X_{0}(k)$ and 
the given sequence $X_{i}(k)$. The results represent the rank of influencing power: Private-owned enterprises、State-owned enterprises、Hongkong-Macao-Taiwan holding enterprises、 foreign-owned enterprises、Other-type holding enterprise、 collective-owned enterprise.

Table 2. The grey-relational coefficient.

\begin{tabular}{llllllll}
\hline Industry & $\boldsymbol{\xi}_{\mathbf{0 1}}(\boldsymbol{k})$ & $\boldsymbol{\xi}_{\mathbf{0 2}}(\boldsymbol{k})$ & $\xi_{\mathbf{0 3}}(\boldsymbol{k})$ & $\xi_{\mathbf{0 4}}(\boldsymbol{k})$ & $\boldsymbol{\xi}_{\mathbf{0 5}}(\boldsymbol{k})$ & $\boldsymbol{\xi}_{\mathbf{0 6}}(\boldsymbol{k})$ & $\boldsymbol{\xi}_{\mathbf{0 1}}(\boldsymbol{k})$ \\
\hline 1 & 0.934 & 0.714 & 0.720 & 0.711 & 0.713 & 0.734 & 0.934 \\
2 & 0.927 & 0.840 & 0.874 & 0.839 & 0.838 & 0.856 & 0.927 \\
3 & 0.979 & 0.953 & 0.966 & 0.953 & 0.953 & 0.956 & 0.979 \\
4 & 0.654 & 0.568 & 0.608 & 0.718 & 0.573 & 0.574 & 0.654 \\
5 & 0.546 & 0.458 & 0.561 & 0.484 & 0.483 & 0.473 & 0.546 \\
6 & 0.881 & 0.831 & 0.889 & 0.829 & 0.827 & 0.834 & 0.881 \\
7 & 0.554 & 0.544 & 0.765 & 0.576 & 0.557 & 0.552 & 0.554 \\
8 & 0.590 & 0.547 & 0.714 & 0.565 & 0.555 & 0.550 & 0.590 \\
9 & 0.353 & 0.334 & 0.455 & 0.367 & 0.377 & 0.337 & 0.353 \\
10 & 0.745 & 0.740 & 0.822 & 0.766 & 0.823 & 0.744 & 0.745 \\
\hline
\end{tabular}

Table 3. The equal relational grade and the orders.

\begin{tabular}{lllllll}
\hline $\boldsymbol{r}_{\mathbf{0} \boldsymbol{i}}$ & $\boldsymbol{r}_{\mathbf{0 1}}$ & $\boldsymbol{r}_{\mathbf{0 2}}$ & $\boldsymbol{r}_{\mathbf{0 3}}$ & $\boldsymbol{r}_{\mathbf{0 4}}$ & $\boldsymbol{r}_{\mathbf{0 5}}$ & $\boldsymbol{r}_{\mathbf{0 6}}$ \\
\hline GRG & 0.7162 & 0.6529 & 0.7374 & 0.6807 & 0.6698 & 0.6611 \\
Orders & 2 & 6 & 1 & 3 & 4 & 5 \\
\hline
\end{tabular}

\section{Conclusion}

From the analysis above, the influence that state-owned cultural enterprises impact on the cultural industry is not the strongest. The reasons for this phenomenon are list as follows.

\subsection{Institutional Backwardness}

Institutional backwardness is the fundamental factor restricting the development of Chinese state-owned cultural enterprises. Too much intervention from The Chinese government, leading to problems such as weakness of risk consciousness, outmoded management theory and mode, lack of investment talent, etc, which seriously restrict the development of Chinese state-owned cultural enterprises[7].

\subsection{Financing Dilemma}

The difficulty of financing limits the development and expansion of state-owned cultural enterprises. At present, the imperfect of the financing system and the financing environment have become an obstacle to restrict the effective financing of the state-owned enterprises. Therefore, establishment of the innovative financing system is an urgent issue to support the capital market financing [8].

\subsection{Lacks the Core Competitiveness}

Chinese enterprises, especially state-owned enterprise, were affected by planned economy in the past, lacked competition consciousness generally, and few enterprises cultivated the core competence consciously. The Internet has been developing rapidly in recent years, Baidu, Tencent, Sina and other private enterprises, have monopolized network culture world, with their emerging field of technology, talents and advanced management system. It is difficult for State-owned cultural enterprises to compete with private enterprises because of losing the first mover advantage [9].

Under the contemporaneous background of competitive globalization, however, the management of enterprises in China still keeps a low level at present, which starts at a low point in production, technology and service fields. Many enterprises have no core competence because of their poor quality [10].

In addition to science and technology, talent is one of the key factors to enhance the core competitiveness of enterprises. An enterprise cannot ignore the construction of the talent team, which is related to the sustainable development. As the most valuable human resources, enterprises must pay special attention to the cultivation of senior management personnel, to promote the establishment of advanced evaluation and incentive mechanism.

\subsection{Single Format of the State-Owned Cultural Enterprises}

Large-scale foreign cultural enterprises develop more rapidly than Chinese enterprises, with its whole industry chain and the mutual support of each link. Due to government monopoly, industry barriers and other reasons, the main business of state-owned cultural enterprises are mainly concentrated on a single area. So that the size of the enterprise is greatly limited. These factors have constrained the development of cultural productive forces, resulting in cultural products that cannot meet the growing cultural needs of people.

\section{Advice}

We are acutely aware of that our culture industry still exist many problems compared with western developed countries. Such as institutional construction, capital operation, policies and regulations formulated, brand construction and talent cultivation.

\subsection{Modern Enterprise System}

The way to speed up the development of the state-owned cultural enterprises is perfecting the management system. Faced to the arduous task of development, the government must take effective measures to carry out the cultural industrialization upgrading [11]. The establishment of state cultural property management system could reflect the strategic position and the value of state-owned cultural enterprises [12].

\subsection{Public Finance Expenditure}

Due to the special nature, state-owned cultural enterprises must pursue both economic viability and social responsibility. In view of this, the government should realize the important 
role of the state-owned cultural enterprises and increase the financial investment.

\subsection{Mergers and Acquisitions}

The state-owned cultural enterprises cannot rely on their own strength, owing to the problems existed in these enterprises such as small scale and single format. The government should build a number of large-scale cultural enterprises to establish the whole industry chain through joint, mergers and restructuring [13].

The specific method to be the bellwether is striving to possess advanced digital and network technology of private enterprises, then combined with their own advantages. On the other hand, State-owned cultural enterprises can also mergers with overseas cultural enterprises to enter the overseas cultural market.

\subsection{Market Legal Framework}

All industries cannot develop well without the support and guarantee of laws and regulations. It is easy to appear illegal behavior in cultural industry because of its special nature, especially reflected in the intellectual property rights. The government should profit from the foreign experience to speed up the construction and perfection of laws and regulations. A special law enforcement team can strengthen the supervision of the cultural market to ensure the healthy and rapid development of the cultural market.

\subsection{Shareholding System}

In recent years, some of China's outstanding enterprises, as pioneers in the exploration of joint-stock reform, have taken a firm pace, such as Haier group, Legend Group, Changhong group. And some other large enterprises of state-owned monopoly industries, have also carried out a bold attempt ,such as CNPC、Sinopec、China Telecom, China Unicom, etc[14]. Through this way these enterprises could get worldwide fame and step into international market [15].

This clearly indicates that Shareholding system is the direction of state-owned cultural enterprises system reform.

\section{References}

[1] J. Lin, Research on Promoting the Development of State-owned Cultural Enterprises. Henan Social Sciences, 2014, vol. 12, pp.111-114.
[2] S. Li. Research on the deepening of the cultural system reform in our country in the new period. 2015.

[3] Decision of the CPC Central Committee on Major Issues Pertaining to Deepening Reform of the Cultural System and Promoting the Great Development and Flouring of Social Culture. People's Daily, 2011, vol.10, pp. 001.

[4] J. L. Deng, A Introduction to Grey System Theory. Grey Syst, 1989, vol.1, pp. 1-24.

[5] C.L. Lin and J.L. Lin,. Optimisation of the EDM Process Based on the Orthogonal Array with Fuzzy Logic and Grey Relational Analysis Method. International Journal of Advanced Manufacturing Technology, 2002, 194.

[6] Adeel H. Suhail, N. Ismail,S. V. Wong, N. A. Abdul Jalil. Surface Roughness Identification Using the Grey Relational Analysis with Multiple Performance Characteristics in Turning Operations. Arabian Journal for Science and Engineering, 2012, 374.

[7] Y. L. Gong and Q. Y. Xia, Reform of the Corporate System of the Modern Enterprise System of State-owned Cultural Enterprises. Journal of Huai Hua University, 2001, vol. 27, pp. 37-39.

[8] Y. Li. Financing of the State-owned cultural enterprise and case studies, 2012.

[9] H. C. Gao and X. F. Bu, How to cross the barrier of the development of the state-owned cultural enterprises. China Culture Daily, 2013, vol. 3, pp. 002.

[10] T. Qi, On improving the efficiency of state-owned cultural enterprises from the innovation ability. Manager's Journal, 2010, vol. 14, pp. 62-63.

[11] C. Chen and W. C. Fu, The particularity of the management of the state-owned assets of the cultural enterprises and its policy. Learning and Practice, 2015, vol. 06, pp. 120-125.

[12] N. Pan, Road to the transformation of state-owned cultural enterprises. Study Times, 2015, vol. 10, pp. 004.

[13] H. S. Liao. The traction effect of economic system reform on the reform of the cultural system. South China Journal of Economics, 2003, vol.10, pp. 129-132.

[14] F. M. Men, Shareholding System is the only way for the Reform of State-owned Cultural Enterprises. Shanghai State-owned Assets Management Committee Group, 2014, vol. 1, pp. 46-47.

[15] Y. F. Qi, Shareholding system: the direction of the reform of state-owned cultural enterprises. Comments on Chinese culture industry, 2015, pp. 30-47. 